\title{
Mitigation of Railway Traffic Induced Vibrations: The Influence of Barriers in Elastic Half-Space
}

\author{
Michele Buonsanti, ${ }^{1}$ Francis Cirianni, ${ }^{2}$ Giovanni Leonardi, ${ }^{2}$ Adolfo Santini, ${ }^{1}$ \\ and Francesco Scopelliti ${ }^{2}$
}

${ }^{1}$ Department of Mechanics and Materials (MECMAT), Mediterranean University of Reggio Calabria,
Via Graziella, Feo di Vito, 89100 Reggio Calabria, Italy
${ }^{2}$ Department of Information Science, Mathematics, Electronics, and Transportations (DIMET),
Mediterranean University of Reggio Calabria, Via Graziella, Feo di Vito, 89100 Reggio Calabria, Italy

Correspondence should be addressed to Giovanni Leonardi, giovanni.leonardi@unirc.it

Received 23 January 2009; Revised 6 May 2009; Accepted 9 May 2009

Recommended by Yehia Bahei-El-Din

\begin{abstract}
In this paper, the problem of vibrations induced by trains and their propagation through the soil is studied. Particular attention is focused on the vibration induced by trains in motion and on the effects of such vibrations on the foundations of buildings in proximity of the tracks. The interaction between propagating waves induced by trains in motion and buildings foundations is a problem which does not admit a straightforward analytical solution; thus a solution is given by the use of a model based on the finite elements method. Firstly, we analyze the theoretical aspects of the problem by considering constant or harmonic loads moving along a straight railway track; then, we define a transfer function soil-railway and the response function of the entire system. The study aims to address the wave propagation in an elastic semi-space and the presence in the ground of a discontinuity element, such as a barrier of a given depth is considered. The efficiency variation of barriers is analyzed in function of the different materials used, and different numerical simulations are analyzed in order to study how the wave propagation and the track-soil interaction are influenced by the membrane, seen as damping barrier.
\end{abstract}

Copyright $\odot 2009$ Michele Buonsanti et al. This is an open access article distributed under the Creative Commons Attribution License, which permits unrestricted use, distribution, and reproduction in any medium, provided the original work is properly cited.

\section{Introduction}

The foundations of structures are subject to vibrations due to moving masses, as vehicles in transit, vibrations which can cause damage locally to the foundations, as they can also travel up to the structures in elevation (Figure 1).

In this paper we consider the effects of vibrations due to the transit of locomotives on a railway, analyzing how the presence of material discontinuity, in an elastic semispace has an influence on the transmission of waves generated by a train passing by. The presence of barriers, made in polymeric material, rubber, or in concrete, seems to cause reflection and refraction of the vibrations generated in the ground. There are some references in scientific literature. Francois et al. [1], approached interaction between ground and infrastructures, in presence of vibrations generated by road traffic, while Sheng et al. [2], modelled the propagation of vibrations due to constant or harmonic loads, produced by the movement of trains.

Numerical aspects are developed in detail in Lombaert et al. [3] and Fiala et al. [4], while in Hubert et al. [5], a detailed analysis using the Boundary Element Method, in the dominion of frequency and of time, is developed on a model of elastic semispace. In the work of Andersen and Nielsen [6], a model for the reduction of vibrations of the ground through the use of barriers dipped in the ground and laid between rail track and structure is proposed. In the paper, after some general concepts of theory of the vibrations, the aim is set on the problem in homogenous elastic and isotropic semispace, where a two-dimensional constitutional discontinuity is localized, representing the artificial barrier in the hypothesis set for different materials (rubber, polyurethane, and concrete). 


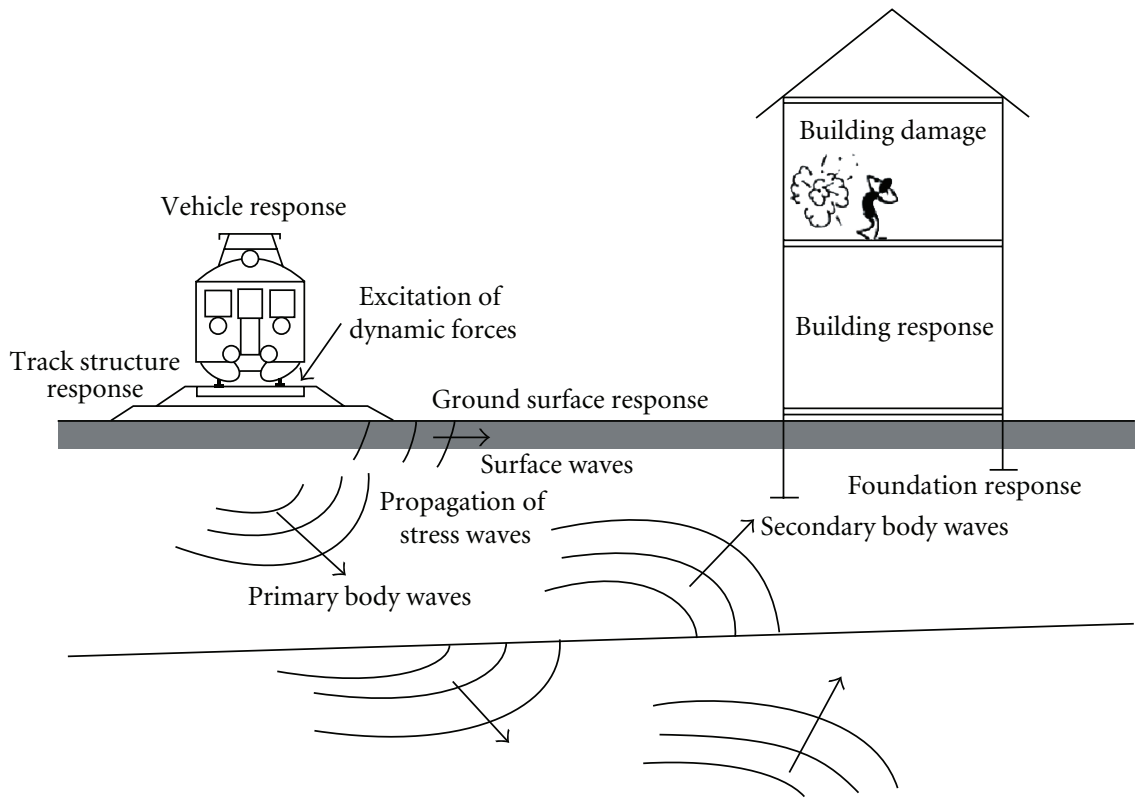

Figure 1: Transmission of induced vibrations.

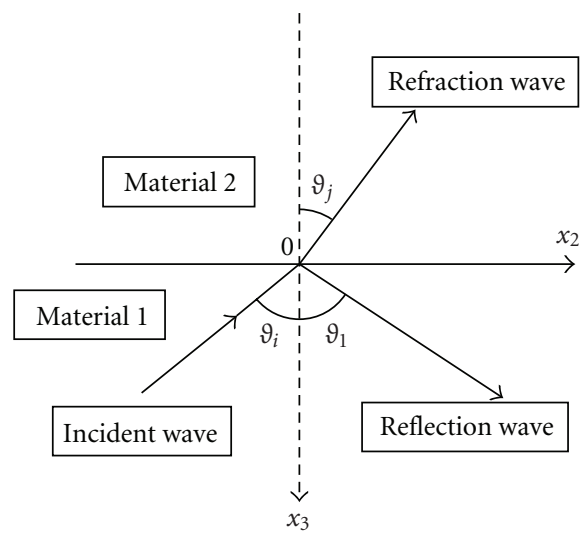

FIgURE 2: Incident wave and reflection.

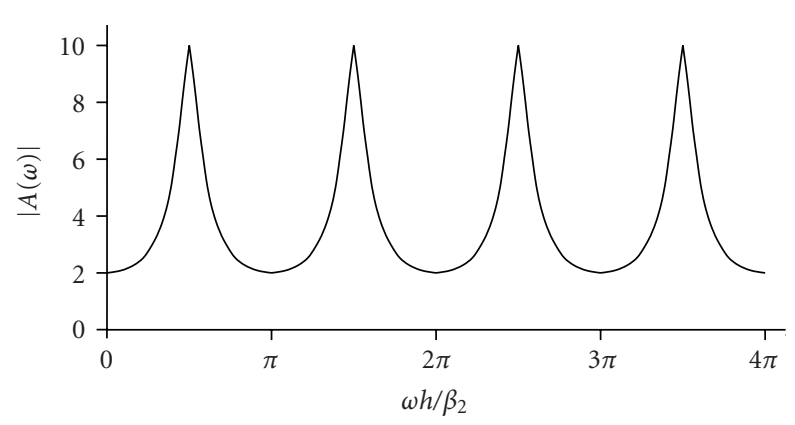

Figure 3: Amplification waves for $Z_{1} / Z_{2}=4$.

Once the case is defined in its theoretical formulation, a numerical simulation with the support of computer application is carried out. What we want to analyze is the variation of the mechanism of propagation of the vibration waves which happens in the semispace, regarding the conditions of quiet, and anyway without the influence of a traveling load. In particular, we observe as the nature of the material used for the realization of the barrier vary, how the conditions of propagation of the waves vary, and their influence, in an equilibrium state, on the contour conditions of an eventual foundation laid under the barrier.

\section{Vibrations Theory}

In regard to the fundamental aspects in the theory of the vibrations, in all this paper we follow the lines expressed in Hartog [7] and Clough and Penzien [8]. Our problem can have a first general organization in the context of the response for harmonic type loads. It is possible to characterize the following fundamental equations in the case of systems without damping:

$$
m \ddot{u}(t)+k u(t)=p_{0} \sin \omega t,
$$

and with damping,

$$
m \ddot{u}(t)+c u(t)+k u(t)=p_{0} \sin \omega t .
$$

The solution of (1) is admitted, from the combination of a complementary solution with a particular solution, in the shape

$$
u(t)=A \sin \omega t+B \cos \omega t+\left(\frac{p_{0} \beta}{\kappa}\right)(1-\beta 2) \sin \omega t .
$$

In the case of (2) the general solution is of the type

$$
\begin{aligned}
u(t)= & e^{-\xi \omega t}\left(A \sin \omega_{D} t+B \cos \omega_{D} t\right)+\frac{p_{0}}{k} \\
& \times \frac{1}{\left(1-\beta^{2}\right)^{2}+(2 \xi \beta)^{2}}\left[\left(1-\beta^{2}\right) \sin \omega t-2 \xi \beta \cos \omega t\right] .
\end{aligned}
$$




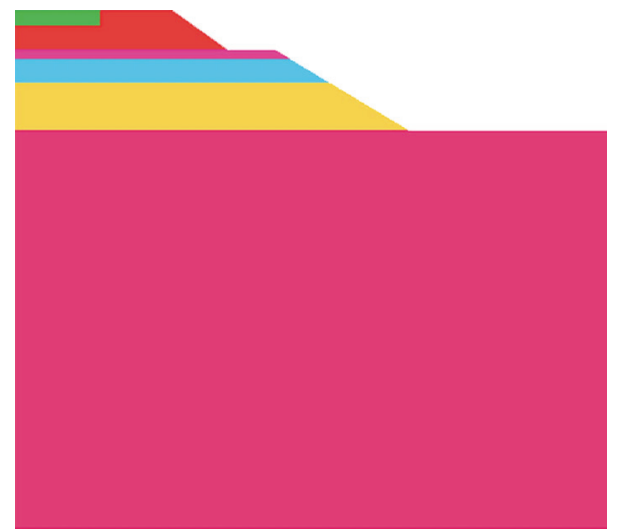

FIGURE 4: Modelling of the railway embankment.

The first term of (4) represents the transitory result, while the second term represents the stationary result, which has the pulsation of the solicitation but is out of sync with the last wave. The factor of dynamics amplification $D$ is defined as the relationship betw.een the amplitude of the stationary response and the static movement produced from the external load. In a generalized manner $D$ is function of the damping ratio and of the frequency relationship and usually it tends to infinite when damping is absent.

\section{Theoretical Aspects in the Model Characterization}

In an elastic semispace we consider that the source of disturbance (train) generates a set of waves which are distributed in the plane system and therefore we can classify the waves plane and classify our problem as a motion of waves within a semi-infinite body, which is assumed, for simplicity, elastic, homogenous, and isotropic. This type of phenomenon is shown in its generality and specificity in the case of the seismic waves as treated in Boschi and Dragoni [9]. We then consider a longitudinal elastic plane wave that propagates in $x$-direction, if we assume the movement $\mathbf{u}$ associated to it as a periodic function of the time, $\mathbf{u}$ can be placed in the form

$$
\mathbf{u}(x, t)=\mathbf{x} a \cos (k x-\omega t+\varphi)
$$

where $a$ is the amplitude, $k$ the wave number, $\varphi$ a constant.

Using the relation between the exponential and trigonometrical functions, and the complex notation, each component of the movement, for a monochromatic wave, can be defined as

$$
u(x, t)=A e^{i(k x-\omega t)},
$$

that represents an oscillation of amplitude $A$ and wavelength $\lambda=2 \pi / \kappa$, which propagates in the direction of the wave

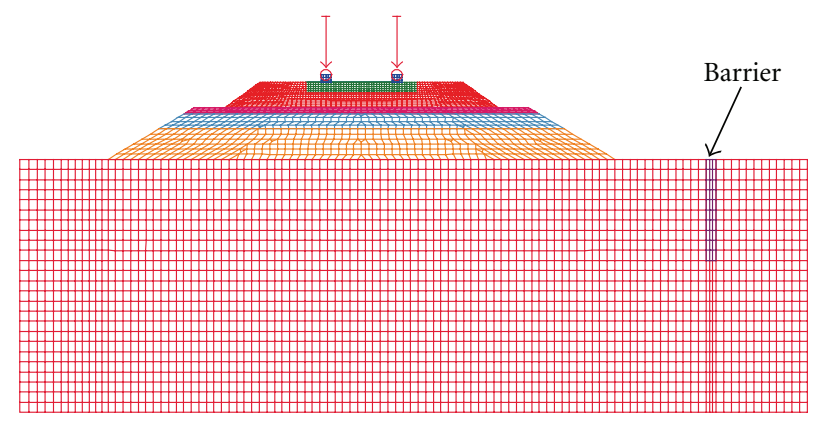

FIgURE 5: Finite element mesh of the two-dimensional model.

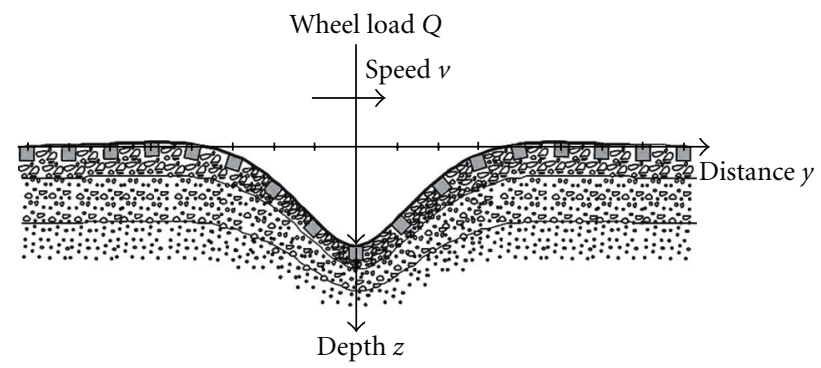

FIGURE 6: Deflection of the track structure from one wheel.

vector $k$ at constant speed (phase speed):

$$
v_{f}=\frac{\omega}{\kappa}
$$

any system of waves can be considered as a superimposition of monochromatic plane waves that move with the group velocity:

$$
v_{g}=\frac{d \omega}{d \kappa}
$$

Equation (8) represents the speed with which the energy is transported and, if $v_{f}$ is different from $v_{g}$, the constant phase surfaces move from an extremity to another in the package of waves while this last one is the same one in motion.

Given such assumption, we consider the elastic semispace as composed of different homogenous elements. Let's assume to form a put in elastic discontinuity, in the cross-sectional sense to the semispace, so to be placed in cross-sectional sense to the wave movement. This eliminates the direct flow of the waves from the source to the site of the structure placing itself as element of filter to the vibrations generated from the movement of the train. Regarding the interaction with the wave, or the set of waves, the discontinuity assumes the role of reflection element and refraction for twodimensional waves. If we consider two elastic semispaces joined with an element of material discontinuity, we may say that $\rho, \alpha, \beta$ are, respectively, the density and the speed of the $j$ elastic waves in the first semispace while $\rho^{*}, \alpha^{*}, \beta^{*}$ are the same amounts in the second semispace (Figure 2 ).

Refraction and reflection of the elastic waves will happen on the discontinuity surface, longitudinal ones, and of crosssectional ones which can transform one in the other when 


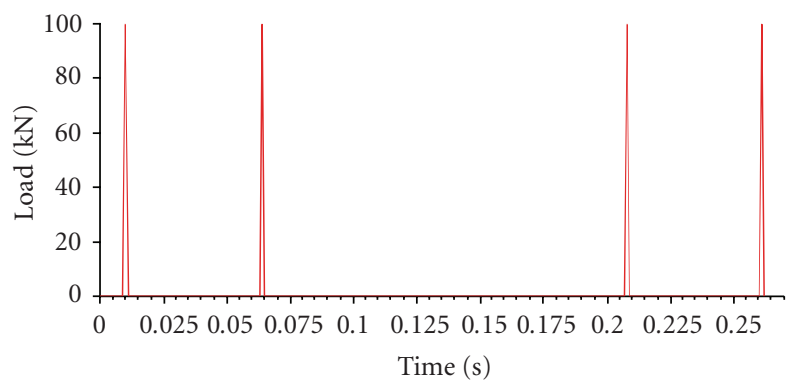

FIGURE 7: Load distribution of a moving wheel travelling at speed of $200 \mathrm{~km} / \mathrm{h}$.

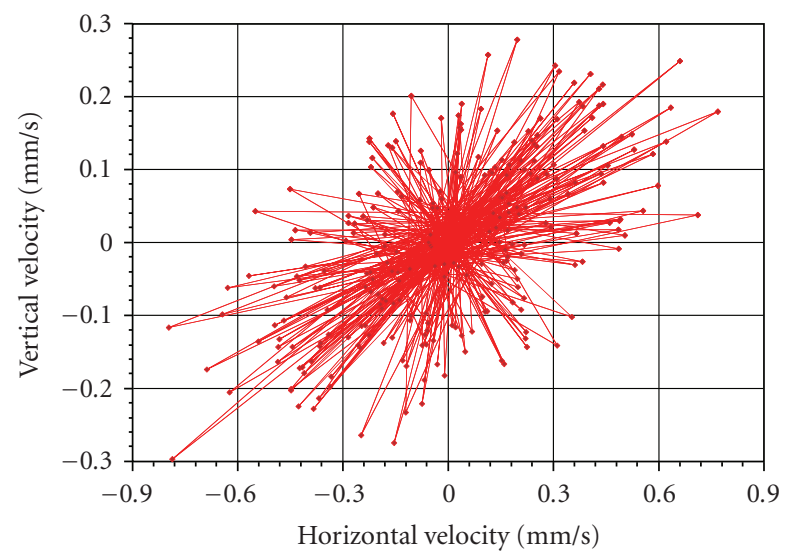

(a)

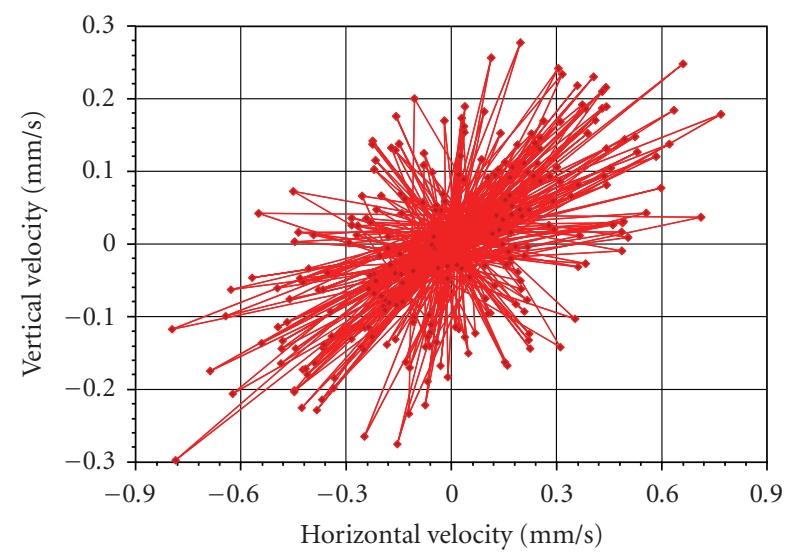

(b)

Figure 8: Nodes velocity $(\mathrm{m} / \mathrm{s})$ responses for a train speed of $200 \mathrm{~km} / \mathrm{h}$.

inciting on the surface that separates the two semispaces. In accordance with Graff [10], the coefficient of reflection or refraction $c_{i j}$ assumes the form:

$$
c_{i j}=\frac{2 \rho_{i} \beta_{i} \cos \theta_{i}}{\rho_{i} \beta_{i} \cos \theta_{i}+\rho_{j}^{*} \beta_{j}^{*} \cos \theta_{j}} .
$$

The contour conditions, on plan $x_{3}=0$ are the continuity of stress and the movement.

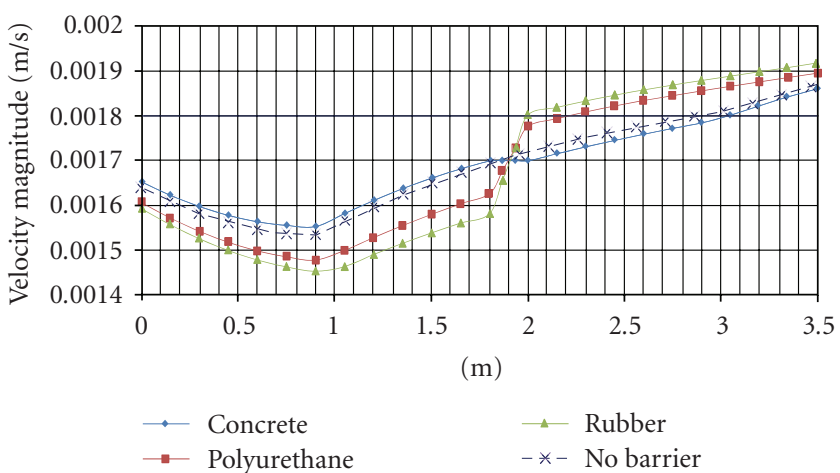

FIGURE 9: Trend of the velocity with the increase of the distance from embankment at the depth of $1 \mathrm{~m}$.

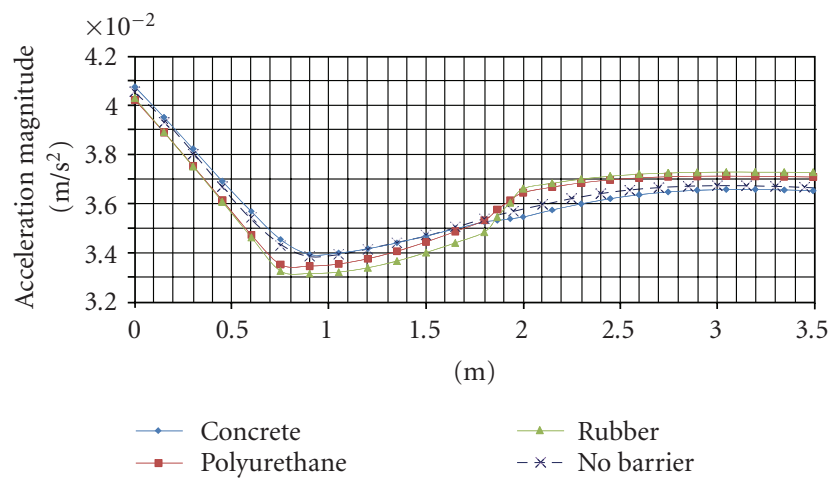

Figure 10: Trend of the acceleration with the increase of the distance from embankment at the depth of $1 \mathrm{~m}$.

We assume that given a monochromatic wave incident with frequency $\omega$, number of wave $k_{1}$ and travelling unitary amplitude in the semispace in direction- $x_{3}$, it produces one cross-sectional movement, in direction $x_{2}$ expressed in the form:

$$
\mathbf{u}\left(x_{3}, t\right)=\exp \left[\omega t+k_{1}\left(x_{3}-h\right)\right], \quad x_{3} \geq h,
$$

after the phenomenon of refraction and reflection the field of movements takes the form:

$$
\begin{aligned}
\mathbf{u}\left(x_{3}, t\right)= & \exp \left[\omega t+k_{1}\left(x_{3}-h\right)\right] \\
& +R^{*} \exp \left[\omega t-k_{2}\left(x_{3}-h\right)\right], \quad x_{3} \geq h,
\end{aligned}
$$

where $R^{*}$ is a coefficient that holds account of all the waves that travel in positive direction $x_{3}$. The contour conditions require that traction on free surface $x_{3}$ is equal to zero, $x_{3}=$ 0 , and that the movement and the traction are continuous on the surface of discontinuity $x_{3}=h$. In agreement with Graff [10], given $Z_{1}, Z_{\text {the } 2}$ as stiffness of the two semispace and $A(\omega)$ the coefficient of the exponential, the module of the latter supplies the amplification of the waves:

$$
|A(\omega)|=\frac{2}{\operatorname{sqr}\left[\cos ^{2}\left(\omega h / \beta_{j}\right)+\left(Z_{2} / Z_{1}\right)^{2} \sin ^{2}\left(\omega h / \beta_{j}\right)\right]} .
$$


TABLE 1: Properties of structural materials.

\begin{tabular}{lcccccc}
\hline $\begin{array}{l}\text { Mechanical } \\
\text { characteristics }\end{array}$ & $\begin{array}{c}\text { Rail } \\
\text { (UIC60) }\end{array}$ & $\begin{array}{c}\text { Sleeper } \\
\text { (concrete) }\end{array}$ & $\begin{array}{c}\text { Traditional } \\
\text { ballast }\end{array}$ & $\begin{array}{c}\text { HMA } \\
\text { subballast }\end{array}$ & $\begin{array}{c}\text { Protective } \\
\text { layer }\end{array}$ & Embankment \\
\hline $\begin{array}{l}\text { Density } \rho \\
\left(\mathrm{kg} / \mathrm{m}^{3}\right)\end{array}$ & 7850 & 2400 & 1250 & 2200 & 2000 & 1000 \\
$\begin{array}{l}\text { Modulus } E \\
(\mathrm{MPa})\end{array}$ & 210000 & 30000 & 130 & 6000 & 160 & 80 \\
Poisson's Ratio $\nu$ & 0.30 & 0.15 & 0.30 & 0.40 & 0.45 & 0.50 \\
\hline
\end{tabular}

TABle 2: Properties of barriers.

\begin{tabular}{lcccc}
\hline $\begin{array}{l}\text { Mechanical } \\
\text { characteristics }\end{array}$ & $\begin{array}{c}\text { Density } \rho \\
\left(\mathrm{kg} / \mathrm{m}^{3}\right)\end{array}$ & $\begin{array}{c}\text { Modulus } E \\
(\mathrm{MPa})\end{array}$ & $\begin{array}{c}\text { Poisson's } \\
\text { ratio } \nu\end{array}$ & $\begin{array}{c}\text { Dumping } \\
\text { ratio } \eta\end{array}$ \\
\hline $\begin{array}{l}\text { Concrete } \\
\begin{array}{l}\text { Polyurethane } \\
\text { (elastomer) }\end{array}\end{array}$ & 2500 & 25000 & 0.15 & 0.04 \\
Rubber chip & 1170 & 25 & 0.50 & 0.08 \\
\hline
\end{tabular}

Equation (12) is a periodic function of the frequency $\omega$ with maximums in correspondence of the values:

$$
\omega_{n}=(2 n-1)\left(\frac{\pi}{2}\right)\left(\frac{\beta_{j}}{h}\right) .
$$

Figure 3 shows the diagram of amplification of the waves.

\section{Modeling and Simulation: The Track-Subsoil Model}

In this paragraph we show a numerical analysis, using a software for defined elements, on a two-dimensional modeling of the studied system.

4.1. Model Characteristics. In the proposed model the rail track is the conventional one, and the elements that compose it are (Figure 4)

(i) a protective compacted layer $30 \mathrm{~cm}$ thick of sand/ gravel (called, in the Italian railways, supercompact);

(ii) a $12 \mathrm{~cm}$ subballast layer made of bituminous (hotmix asphalt) concrete;

(iii) a traditional ballast layer $35 \mathrm{~cm}$ thick;

(iv) an embankment $60 \mathrm{~cm}$ high.

The dimensional characteristics of the elements above indicated are those requested by the Italian standard (RFI) for high speed lines.

Moreover, to analyze the propagation process of the vibrations in the soil, it has been considered a thickness of the support soil of the embankment equal to a total $5 \mathrm{~m}$.

The materials properties used in the model were derived from tests and available experimentations in literature. Table 1 lists the physical-mechanical characteristics for the soil and track structure.

Finally a discontinuity $(10 \mathrm{~cm}$ thick and $2 \mathrm{~m}$ deep $)$ in the semispace at a given distance from the rail track $(2 \mathrm{~m}$ from the embankment) is considered, considering the passage of a high speed locomotive (ETR 500) with 4 wheels for car.

The effects of discontinuity is estimated considering three different materials whose properties are shown in Table 2.

4.2. Finite Element Analyses of Train-Induced Ground Vibrations. The finite element simulations of train-induced ground vibrations was developed, using the ADINA software, considering a two-dimensional finite element model perpendicular to the track (two-dimensional perpendicular model).

The two-dimensional model is composed of 7517 elements and 8533 nodes (Figure 5). The elements consisted of four-node solid element for ballast, HMA subballast, protective layer and embankment and nine-node solid element for rail and sleeper. Furthermore, the rail pad was modeled with parallel discrete springs and dampers (spring constant $K=11.2 \cdot 10^{8} \mathrm{~N} / \mathrm{m}$ and damper constant $c=$ $\left.12 \cdot 10^{4} \mathrm{Ns} / \mathrm{m}\right)$.

For these elements, under the accepted hypothesis of viscose-elastic behavior, the input parameters for the materials characterization, are the modulus of elasticity $(E)$, Poisson's ratio $(v)$, density $(\rho), \alpha$ and $\beta$ Rayleigh's coefficients for the definition of the damping matrix.

The acting forces are a sequence of axial loads, moving like the train (the loads are similar to those of an ETR 500 locomotive) (Figure 6).

The forces are applied using a time function that represents the time history of the force in the considered node. During the simulations the loads were applied four times, reproducing the passing of four axes. The loads can be thought of as triangular pulses distributed over the wheelrail surface of contact as shown in Figure 7.

All the finite element analyses in this study were performed in the time domain. The time step of the analyses was fixed and set to 0.001 second.

Figure 8 shows the variation of velocity ( $y$-direction and $z$-direction) of the middle node under truck and of a node at the distance of $1.5 \mathrm{~m}$ from the embankment. The orbits of 


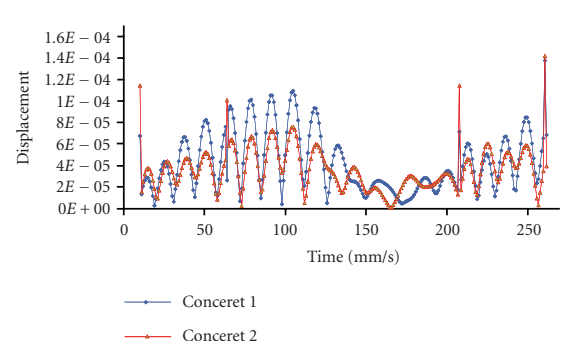

(a)

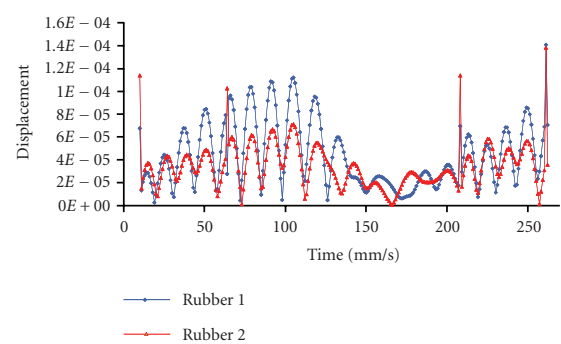

(d)

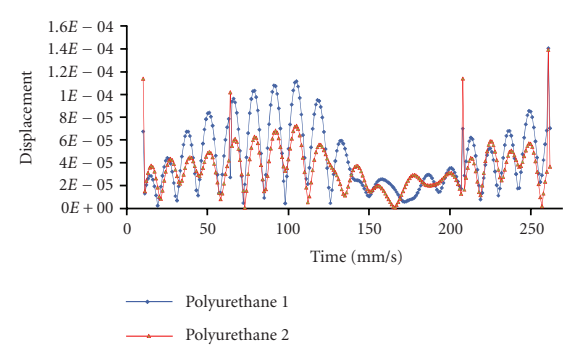

(g)

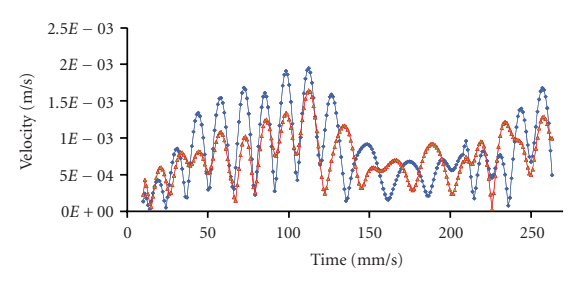

$\longrightarrow$ Conceret 1
$\longrightarrow$ Conceret 2

(b)

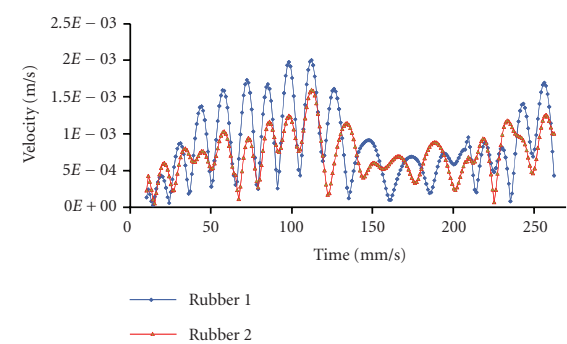

(e)

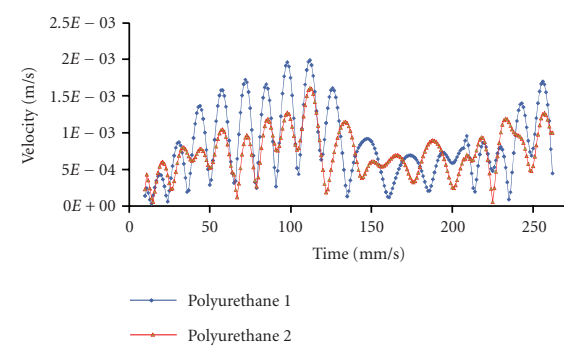

(h)

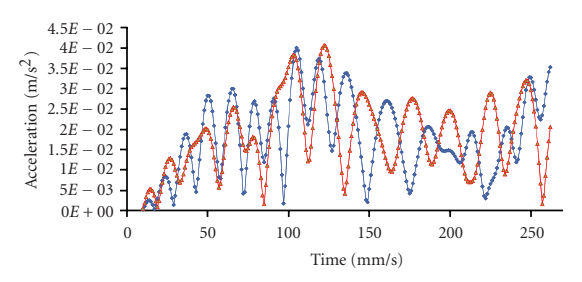

- Conceret 1

(c)

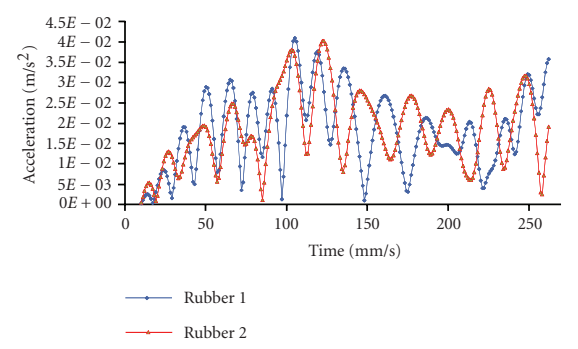

(f)

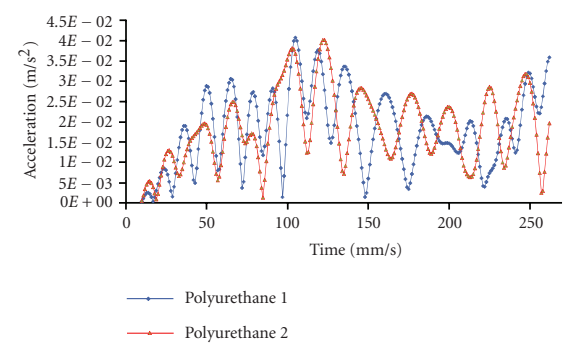

(i)

FIGURE 11: Trend of displacement, velocity, and acceleration in two nodes located before and after the barrier.

vertical to horizontal particle motions were mostly counter clockwise; this could indicate the presence of Rayleigh waves [11].

\section{Results}

The graphs of the outcomes of the various analyses are shown in Figures 9 and 10.

To estimate the effectiveness of the barrier we have estimated the dynamic characteristics (speed and acceleration) before and after the discontinuity, in correspondence of an eventual foundation plan of a building placed at a distance of 1.5 meters from the barrier.

As a general result of the analyses, as illustrated in Figures 9 and 11, for the considered loads, it is concluded that, when the load is travelling with the speed of $200 \mathrm{Km} / \mathrm{h}$, concrete barriers provide a more efficient vibration shielding than the rubber and polyurethane barriers.

Figure 11 shows, for the three kinds of barrier, the course of the displacement, velocity, and acceleration in time.

The results given in Figures 9 and 11 supply useful information for the making of barriers, especially when it is required to respect regulation's limit for vibration, as expressed in terms of displacements and velocities (i.e., Italian regulation UNI 9916/2220).

\section{Conclusions}

The results of the proposed elaborations at the finite elements have been finalized to the assessment of the incidence of the barrier on the vibration state induced from the passage of a high speed locomotive. The response of three different materials for the barrier was confronted and the following conclusions can be made:

(i) concrete seems to provide a better reduction of the vibration. In spite of the greater density of the material it involves an increase of the reflection phenomena and a consequent increase of the phenomenon at the top side of the barrier (Figures 9 and $10)$;

(ii) polyurethane and rubber chip materials seem to respond in a similar way to the solicitations; however their damping contribution, in the analyzed geometric configuration, do not contribute meaningfully.

The results obtained were given with the use of different materials for the barrier, in identical geometrical conditions, in size and position of the proposed damping barriers. A follow up to the presented study, requiring further analyses, is in course, to estimate the influence of the position and of the thickness of the barriers on their dampening ability. 


\section{References}

[1] S. Francois, L. Pyl, H. R. Masoumi, and G. Degrande, "The influence of dynamic soil-structure interaction on traffic induced vibrations in buildings," Soil Dynamics and Earthquake Engineering, vol. 27, no. 7, pp. 655-674, 2007.

[2] X. Sheng, C. J. C. Jones, and M. Petyt, "Ground vibration generated by a load moving along a railway track," Journal of Sound and Vibration, vol. 228, no. 1, pp. 129-156, 1999.

[3] G. Lombaert, G. Degrande, and D. Clouteau, "Numerical modelling of free field traffic-induced vibrations," Soil Dynamics and Earthquake Engineering, vol. 19, no. 7, pp. 473$488,2000$.

[4] P. Fiala, G. Degrande, and F. Augusztinovicz, "Numerical modelling of ground-borne noise and vibration in buildings due to surface rail traffic," Journal of Sound and Vibration, vol. 301, no. 3-5, pp. 718-738, 2007.

[5] W. Hubert, K. Friedrich, G. Pflanz, and G. Schmid, "Frequency- and time-domain BEM analysis of rigid track on a half-space with vibration barriers," Meccanica, vol. 36, no. 4, pp. 421-436, 2001.

[6] L. Andersen and S. R. K. Nielsen, "Reduction of ground vibration by means of barriers or soil improvement along a railway track," Soil Dynamics and Earthquake Engineering, vol. 25, no. 7-10, pp. 701-716, 2005.

[7] J. P. D. Hartog, Mechanical Vibrations, Dover, Oxford, UK; Oxford University Press, Oxford, UK, 1975.

[8] R. W. Clough and J. Penzien, Dynamics of Structures, McGrawHill, Singapore, 1985.

[9] E. Boschi and M. Dragoni, Sismologia, UTET, Torino, Italy, 2000.

[10] K. F. Graff, Wave Motion in Elastic Solids, Dover, Oxford, UK, 1991.

[11] L. Hall, "Simulations and analyses of train-induced ground vibrations in finite element models," Soil Dynamics and Earthquake Engineering, vol. 23, no. 5, pp. 403-413, 2003. 

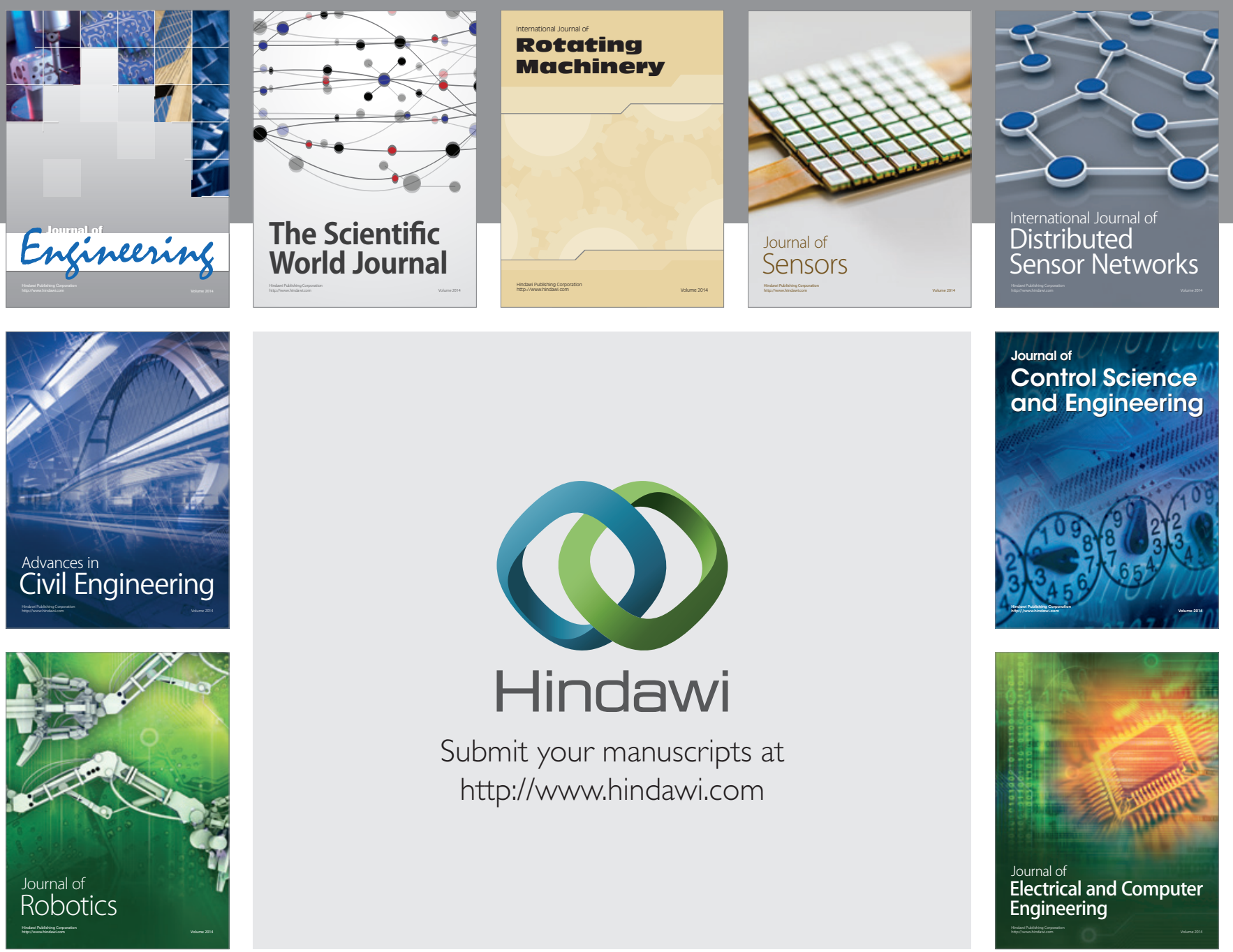

Submit your manuscripts at

http://www.hindawi.com
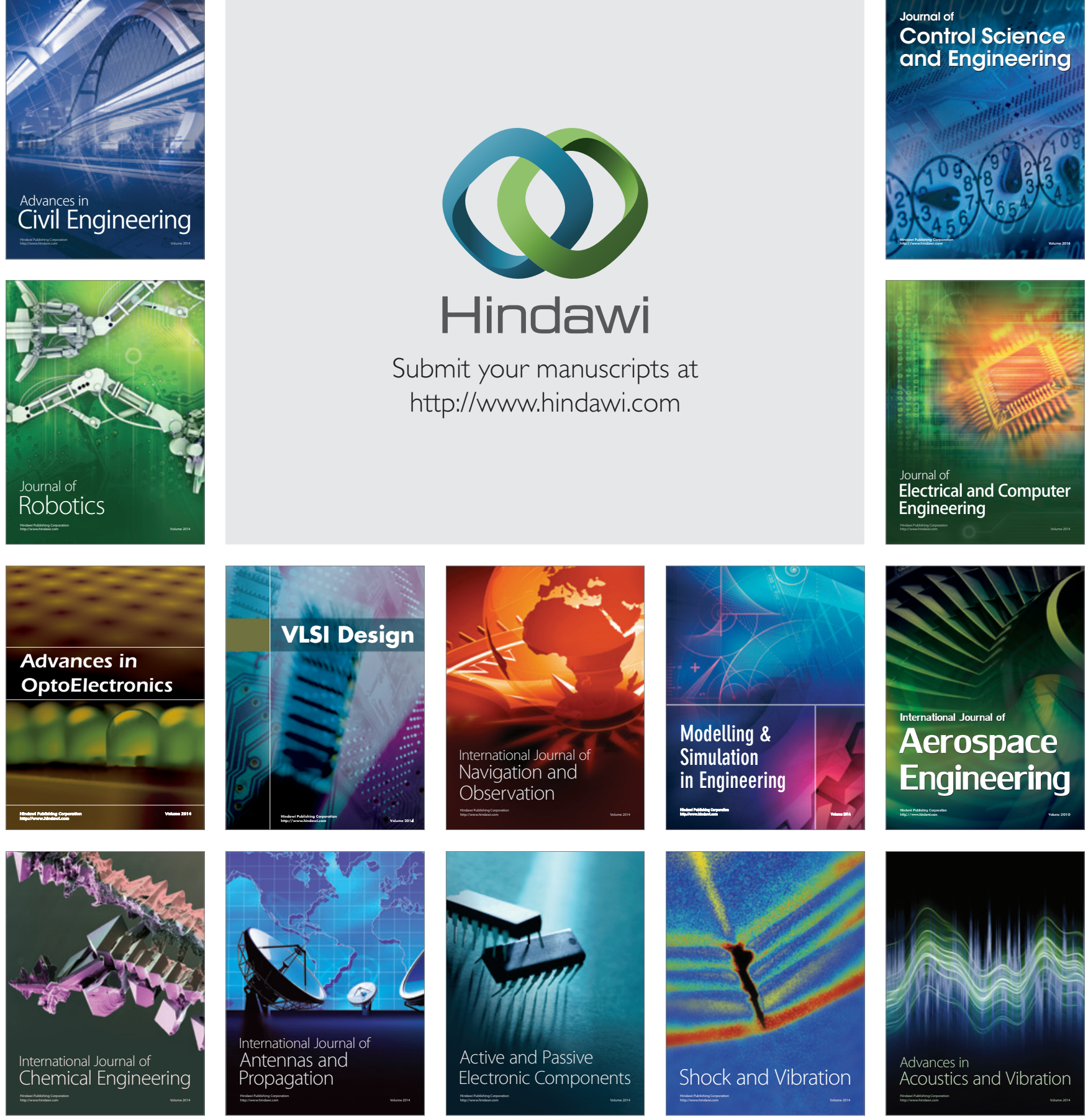